\title{
Transverse propagation in an expanded PSpice model for cardiac muscle with gap-junction ion channels
} Lakshminarayanan Ramasamy ${ }^{1,2}$ and Nicholas Sperelakis*1

\author{
Address: ${ }^{1}$ Dept. of Molecular \& Cellular Physiology University of Cincinnati College of MedicineCincinnati, OH 45267-0576, USA and ${ }^{2}$ Dept. of \\ Electrical Computer Engineering and Computer ScienceUniversity of Cincinnati College of Engineering Cincinnati, OH 45219, USA \\ Email: Lakshminarayanan Ramasamy - lakshmr@ececs.uc.edu; Nicholas Sperelakis* - spereln@ucmail.uc.edu \\ * Corresponding author
}

Published: 28 July 2006

BioMedical Engineering OnLine 2006, 5:46 doi:10.1186/1475-925X-5-46
Received: 07 May 2006

Accepted: 28 July 2006

This article is available from: http://www.biomedical-engineering-online.com/content/5/I/46

(c) 2006 Ramasamy and Sperelakis; licensee BioMed Central Ltd.

This is an Open Access article distributed under the terms of the Creative Commons Attribution License (http://creativecommons.org/licenses/by/2.0), which permits unrestricted use, distribution, and reproduction in any medium, provided the original work is properly cited.

\begin{abstract}
Transverse propagation was previously found to occur in a two-dimensional model of cardiac muscle using the PSpice software program for electronic circuit design and analysis. Longitudinal propagation within each chain, and transverse propagation between parallel chains, occurred even when there were no gap-junction $(\mathrm{g}-\mathrm{j})$ channels inserted between the simulated myocardial cells either longitudinally or transversely. In those studies, there were pronounced edge (boundary) effects and end-effects even within single chains. Transverse velocity increased with increase in model size. The present study was performed to examine boundary effects on transverse propagation velocity when the length of the chains was held constant at 10 cells and the number of parallel chains was varied from 3 to 5 , to 7 , to 10 , and to 20 . The number of $g$-j channels was either zero, both longitudinally and transversely $(0 / 0)$, or $100 / 100$. Some experiments were also made at $100 / 0,1 / 1$, and 10/10. Transverse velocity and overall velocity (both longitudinal and transverse components) was calculated from the measured total propagation time (TPT), i.e., the elapsed time between when the first action potential (AP) and the last AP crossed the zero potential level. The transverse g-j channels were placed only at the ends of each chain, such that propagation would occur in a zigzag pattern. Electrical stimulation was applied intracellularly between cells AI and A2. It was found that, with no $g$-j channels $(0 / 0)$, overall velocity increased almost linearly when more and more chains were placed in parallel. In contrast, with many g-j channels (100/100), there was a much flatter relationship between overall velocity and number of parallel chains. The difference in velocities with $0 / 0$ channels and 100/100 channels was reduced as the number of chains was increased. In conclusion, edges have important effects on propagation velocity (overall and transverse) in cardiac muscle simulations.
\end{abstract}

\section{Background}

Successful transmission of excitation from one myocardial cell to the next contiguous myocardial cell can occur without the necessity of gj-channels between the cells. This has been demonstrated to be possible in theoretical and modeling studies by Sperelakis and colleagues [1-4]. In addition, the essential phenomenon in electric field
(EF) transmission has been confirmed by other laboratories, [5-7]. As was stated in the 1977 paper of Sperelakis and Mann [1], for the EF mechanism to work successfully, the junctional membrane must be more excitable than the contiguous surface sarcolemma. The fact that the junctional membranes (i.e., the intercalated disks) have a higher concentration (density) of fast $\mathrm{Na}^{+}$channels than 
the surface sarcolemma $[6,8-10]$ should cause them to be more excitable than the surface membrane.

Kucera et al. [10] did a simulation study of cardiac muscle in which they determined how conduction velocity varied as a function of the gap-junction resistance (i.e., number of gj-channels) while varying the fraction of fast $\mathrm{I}_{\mathrm{Na}}$ channels located in the junctional membranes. For a $10 \mathrm{~nm}$ (100 $\AA$ ) cleft width and $50 \%$ of the $\mathrm{I}_{\mathrm{Na}}$ channel located in the junctional membranes, they found that conduction still occurred at a velocity of about $20 \mathrm{~cm} / \mathrm{sec}$ when cell coupling was reduced to $10 \%$ of normal. Velocity was about $10 \mathrm{~cm} / \mathrm{sec}$ when coupling was $1 \%$ of normal. Consistent with our previous report [11] they observed that the EF mechanism actually slowed velocity by a significant amount when there was strong ("normal") coupling.

In biological studies on connexon43 knockout mice, and therefore virtually absent in gi-channels in their hearts, it was shown that propagation velocity only was slowed, but not blocked [12-15]. And these mice survive. Therefore, it seems clear that the presence of gj-channels is not essential for propagation of excitation in the heart. But when hearts do contain gj-channels (e.g., mammals and adult birds), propagation velocity is speeded up. The PSpice simulation studies suggest that too many gj-channels (e.g., more than 100 channels per junction) causes the propagation velocity to greatly exceed the physiological range. In biological experiments, Rohr et al. [7] found that partial uncoupling of the heart (using $10 \mu \mathrm{m}$ palmitoleic acid) actually improved impulse conduction by converting unidirectional block to bidirectional propagation (although slower).

Transverse propagation was previously found to occur in a two-dimensional model of cardiac muscle using the PSpice software program for electronic circuit design and analysis [16-19]. Longitudinal propagation within each chain and transverse propagation between parallel chains occurred even when there were no gap-junction (g-j) channels inserted between the simulated myocardial cells either longitudinally or transversely. The transverse propagation is probably mediated by the interstitial potential that develops [16-20]. In previous studies, there were pronounced edge (boundary) effects and end-effects even within single chains $[16,20]$. Transverse velocity increased with increase in model size. The present study was performed to examine boundary effects on transverse propagation velocity when the length of the chains was held constant at 10 cells and the number of parallel chains was varied from 3 to 20 .

\section{Methods}

The methods used and the modeling with PSpice were given in great detail in previous papers $[21,22]$. In brief, each myocardial cell was simulated by four basic circuit units; two for the surface sarcolemma (one depicted upwards and one downwards) and one for each junctional membrane at the two ends of the cell (Fig. 1). The cell junctions contained a transverse resistance, the radial resistance of the junctional cleft $\left(\mathrm{R}_{\mathrm{ic}}\right)$. The standard value used for $\mathrm{R}_{\mathrm{jc}}$ was $25 \mathrm{M} \Omega$ (two $50 \mathrm{M} \Omega$ resistors in parallel).

A shunt resistance $\left(\mathrm{R}_{\mathrm{g} j}\right.$, resistance of the gap junction channels) was placed across each cell junction, i.e., from one cell interior to the next (Fig. 1). It was assumed that each gj-channel had a conductance of $100 \mathrm{pS}$, so $\mathrm{R}_{\mathrm{gj}}$ was $100 \mathrm{M} \Omega$ when 100 gj-channels were inserted, and $100,000 \mathrm{M} \Omega$ when no gj-channels were present.
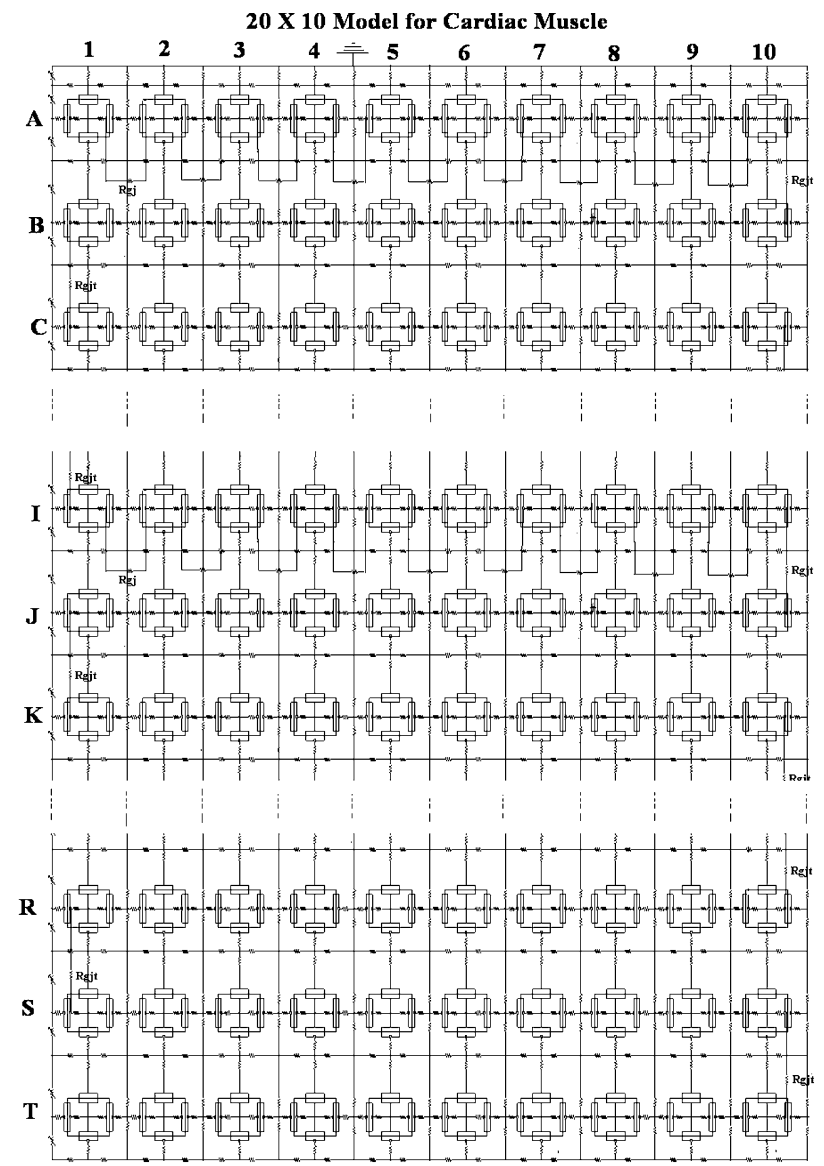

\section{Figure I}

The model for cardiac muscle used for PSpice analysis of propagation. Each chain contained 10 cells, connected longitudinally by cell junctions. The number of chains placed in parallel was varied from 3 (chains $A-C$ ), to 5 (chains $A-E$ ), to 7 (chains A-G), to 10 (chains A-J), and to 20 (chains A-T). The longitudinal resistance between chains $\left(R_{\mathrm{ol} 2}\right)$ had a standard value of $200 \mathrm{~K} \Omega$. 


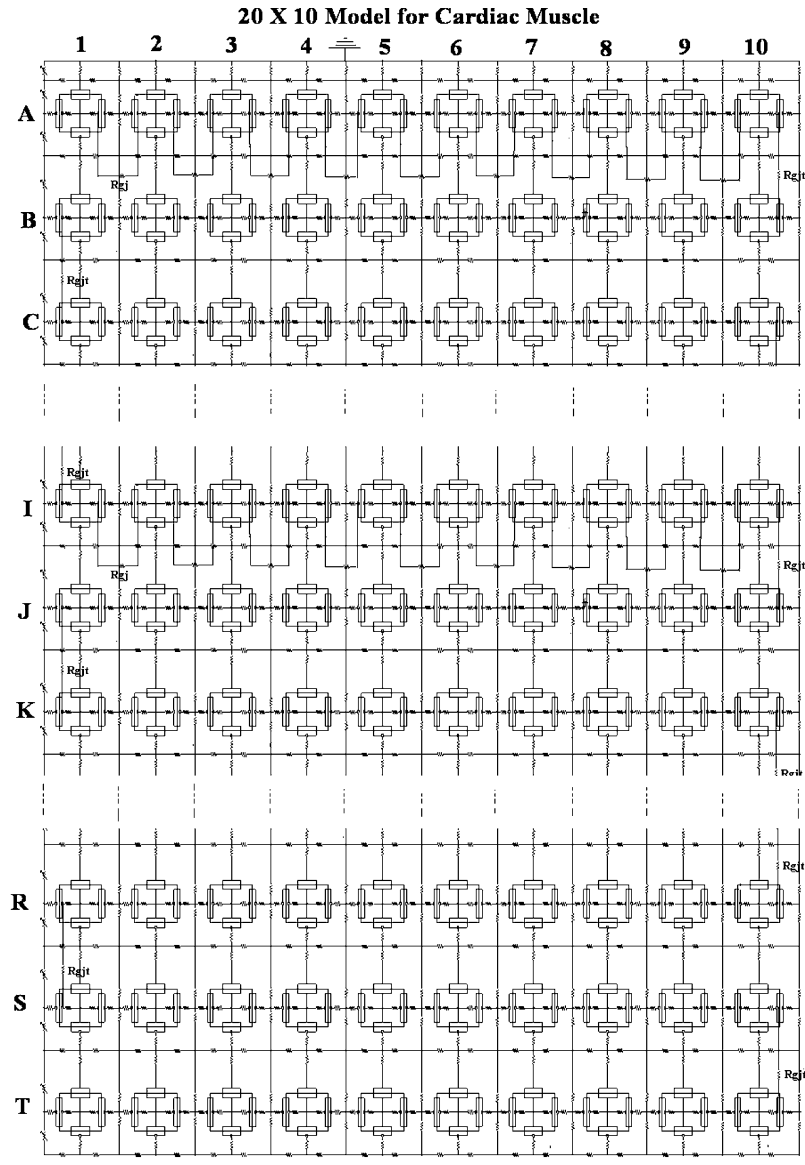

\section{Figure I}

The model for cardiac muscle used for PSpice analysis of propagation. Each chain contained 10 cells, connected longitudinally by cell junctions. The number of chains placed in parallel was varied from 3 (chains $A-C$ ), to 5 (chains $A-E$ ), to 7 (chains A-G), to 10 (chains A-J), and to 20 (chains A-T). The longitudinal resistance between chains $\left(R_{\mathrm{ol} 2}\right)$ had a standard value of $200 \mathrm{~K} \Omega$.

When present, the transverse gi-channels were placed only at the ends of each chain, i.e., between cells A10 and B10, $\mathrm{B} 1$ and $\mathrm{C} 1, \mathrm{C} 10$ and D10, D1 and E1, etc. Thus, propagation could occur in a zigzag pattern [23]. The length of the chains was held constant at 10 cells (cell 1, cell 2, etc), and the number of chains in parallel was varied from 3 to 20 (namely, 3, 5, 7, 10, and 20) (chain A, chain B, etc). Stimulating pulses were applied intracellularly between cells A1 and A2 (rectangular current pulses of $0.25 \mathrm{nA}$ amplitude and 0.25 ms duration).

Overall velocity $\left(\theta_{\text {ov }}\right)$ was calculated from the measured TPT, and assuming that the AP impulse traveled down each chain of 10 cells in succession. The myocardial cells were assumed to be cylinders $150 \mu \mathrm{m}$ long and $16 \mu \mathrm{m}$ in diameter. For example, in the $10 \times 10$ model, the following equation would apply:

$$
\theta_{\mathrm{ov}}=\frac{(100 \text { cells })(150 \mu \mathrm{m} / \text { cell })}{\mathrm{TPT}(\mathrm{ms})}=\frac{(100)\left(15.0 \times 10^{-3} \mathrm{~cm}\right)}{\mathrm{TPT}\left(\times 10^{-3} \mathrm{sec}\right)}
$$

Then, the transverse velocity $\left(\theta_{\mathrm{tr}}\right)$ was calculated from the following equation:

$\Theta_{\mathrm{tr}}=\frac{(10 \text { cells })(16 \mu \mathrm{m} / \text { cell })}{\operatorname{TPT}(\mathrm{ms})}=\frac{(10)\left(1.6 \times 10^{-3} \mathrm{~cm}\right)}{\operatorname{TPT}\left(\times 10^{-3} \mathrm{sec}\right)}$

Hence, for given TPT, the overall velocity would be greater by $93.75 \times$ the transverse velocity.

\section{Results}

The AP records obtained when there were no gj-channels $(0 / 0)$ are shown in Figure 2 for 3 parallel chains (A), 5 parallel chains (B), 7 chains (C), and 10 chains (D). Voltage markers were placed in only cells 1,5 , and 10 of each chain to reduce the complexity. The measured TPT values were $15.6 \mathrm{~ms}$ (A), $17.1 \mathrm{~ms}$ (B), $18.4 \mathrm{~ms}$ (C), and $17.6 \mathrm{~ms}$ (D). The calculated transverse velocity values were, respectively, 0.21, 0.37, 0.52, 0.82 and $1.69 \mathrm{~cm} / \mathrm{sec}$ (Table 2). The calculated overall velocity values were, respectively, $27.9 \mathrm{~cm} / \mathrm{sec}, 43.0 \mathrm{~cm} / \mathrm{sec}, 56.3 \mathrm{~cm} / \mathrm{sec}$, and $84.4 \mathrm{~cm} / \mathrm{sec}$ (Table 2).

The AP records recorded when there were 100 gj-channels, both longitudinally and transversely $(100 / 100)$ are shown in Figure 3 for 3 parallel chain (A), 5 parallel chain (B), 7 chains (C), and 10 chains (D). Voltage markers were present in only cells 1,5 , and 10 of each chain. The measured TPT values were $1.9 \mathrm{~ms}(\mathrm{~A}), 3.9 \mathrm{~ms}$ (B), $5.8 \mathrm{~ms}$ (C), and $8.6 \mathrm{~ms}(\mathrm{D})$. The calculated transverse velocity values were, respectively, 1.68, 1.64, 1.66, 1.67 and 2.00 $\mathrm{cm} / \mathrm{sec}$ (Table 2 ). The calculated overall velocity values were, respectively, 229, 189, 178, and $173 \mathrm{~cm} / \mathrm{sec}$ (Table 2). Note that the latent period to the first AP was markedly increased compared to that in Figure 2 as expected, because with high cell coupling, it is more difficult to produce excitation with a fixed stimulus.

The AP records obtained in the $10 \times 20$ model are shown in Figure 4 for different degrees of cell coupling: 0/0 (A), $1 / 1$ (B), 10/10 (C), and 100/100 (D). The voltage markers were placed in only the two end cells of each chain (cells 1 and 10), to reduce complexity. The TPT values were 18.0 $\mathrm{ms}$ (A), $17.3 \mathrm{~ms}$ (B), $17.0 \mathrm{~ms}$ (C), and $15.2 \mathrm{~ms}$ (D). The calculated transverse velocity values were, respectively, 17 , 18,18 , and $18 \mathrm{~cm} / \mathrm{sec}$. The calculated overall velocity values were, respectively, 166, 173, 176, and $196 \mathrm{~cm} / \mathrm{sec}$. The latent period of the first AP was increased as more and more gj-channels were added, as expected (panels B - D). The latent period in Fig 4D is much larger than that in Fig 


\section{Gj-channels : Longit./Transv. $=\mathbf{0} / 0$}
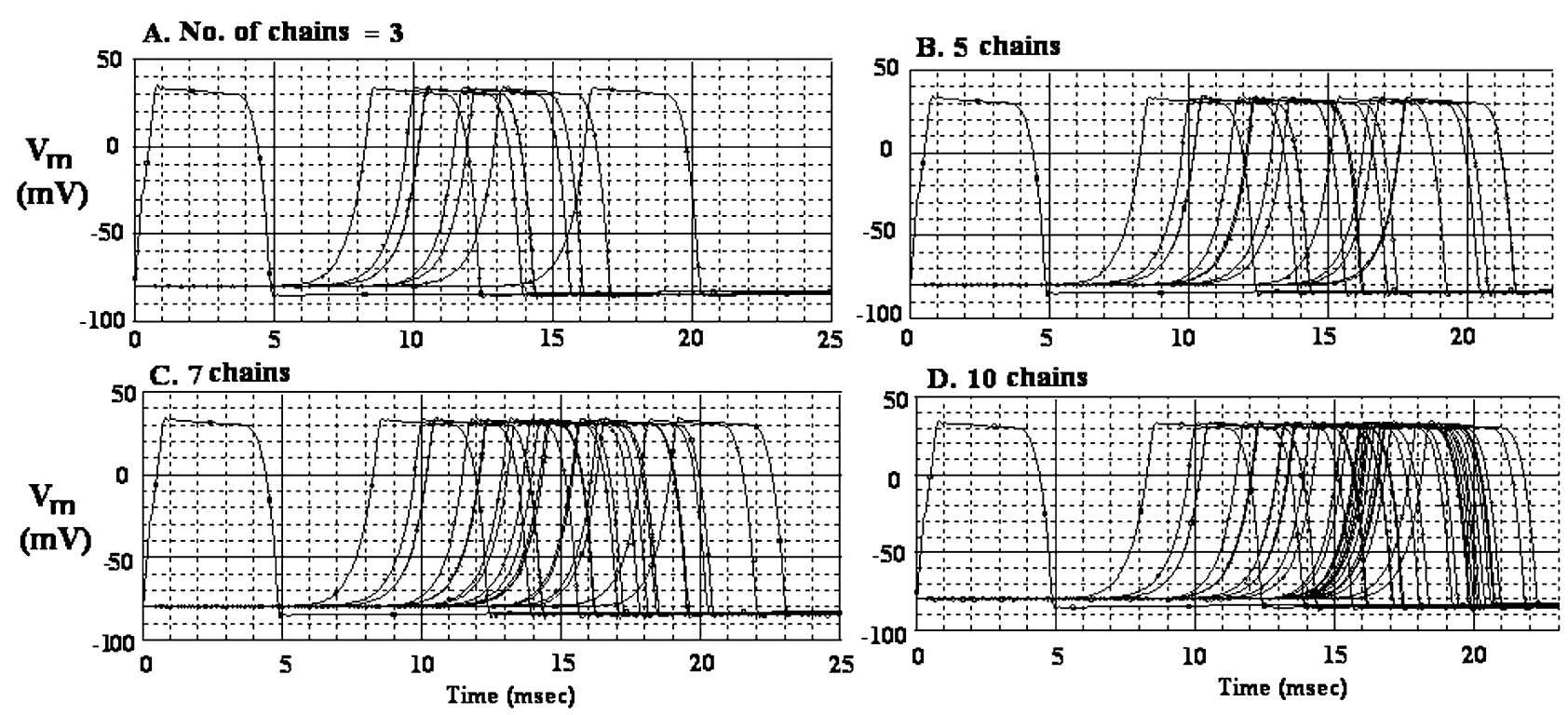

D. 10 chains

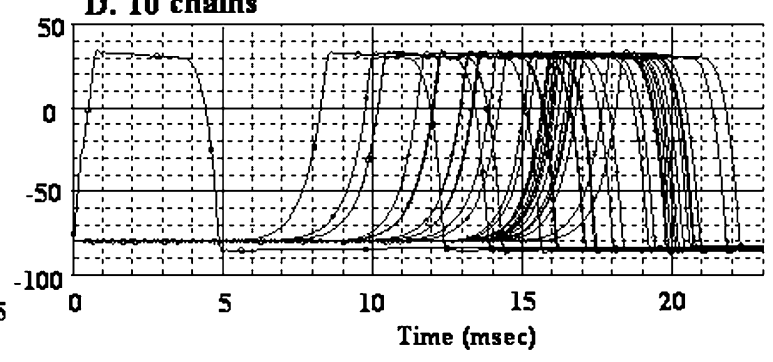

Figure 2

$\mathrm{AP}$ records obtained in the model for cardiac muscle when there were no gj-channels, either longitudinally or transversely (0/ 0). A: 3 chains in parallel. B: 5 chains in parallel. C: 7 chains in parallel. D: 10 chains in parallel. Voltage probes were placed only in cells 1,5 and 10 of each chain in order to reduce the complexity.

Table I: Parameter values used under standard conditions.

\begin{tabular}{lc}
\hline Parameters & Values \\
\hline$C_{m}$ & $300 \mathrm{fF}(30)$ \\
$R_{\mathrm{K}}$ & $71 \mathrm{M} \Omega(7 \mathrm{I} 0)$ \\
$\mathrm{R}_{\mathrm{Na}}$ & $710 \mathrm{M} \Omega(7 \mathrm{l0})$ \\
$\mathrm{E}_{\mathrm{K}}$ & $-94 \mathrm{mV}$ \\
$\mathrm{E}_{\mathrm{Na}}$ & $+60 \mathrm{mV}$ \\
$\mathrm{R}_{\mathrm{d}}$ & $5000 \mathrm{M} \Omega$ \\
$\mathrm{C}_{\mathrm{d}}$ & $30 \mathrm{pF}$ \\
$\mathrm{R}_{\mathrm{or}}$ & $1.0 \mathrm{~K} \Omega$ \\
$\mathrm{R}_{\mathrm{ol}}$ & $1.0 \mathrm{~K} \Omega$ \\
$\mathrm{Ri}$ & $500 \mathrm{~K} \Omega$ \\
$\mathrm{R}_{\mathrm{jc}}$ & $25(50 / 2) \mathrm{M} \Omega$ \\
$\mathrm{R}_{\mathrm{BT}}$ & $200 \mathrm{~K} \Omega$ \\
\hline
\end{tabular}

Values for the junctional units are given in parentheses

$\mathrm{C}_{\mathrm{m}}=$ Total cell capacitance

$\mathrm{R}_{\mathrm{K}}=$ Potassium resistance

$\mathrm{R}_{\mathrm{Na}}=$ Sodium resistance

$\mathrm{E}_{\mathrm{K}}=$ Potassium equilibrium potential

$\mathrm{E}_{\mathrm{N}_{\mathrm{a}}}=$ Sodium equilibrium potential

$R_{d}=$ Resistance in delay circuit for second black-box to bring about

AP repolarization

$\mathrm{C}_{\mathrm{d}}=$ Capacitance in delay circuit for second black-box bring about AP repolarization

$R_{o r}=$ Radial resistance of external fluid

$R_{o l}=$ Longitudinal resistance of external fluid

$R_{i}=$ Longitudinal resistance of intracellular fluid

$R_{i c}=$ Radial resistance of junctional cleft

$R_{B T}=$ Bundle termination resistance
$2 \mathrm{D}$, for the same number of gj-channels, because the size of the interconnected network has been doubled (10 parallel chains to 20).

A graphic summary of the data for $0 / 0$ and 100/100 gjchannels are given in Figure 5. Panel A gives the measured TPT values as a function of the number of parallel chains, panel $\mathrm{B}$ gives the calculated transverse velocity as a function of number of parallel chains, and panel $\mathrm{C}$ gives the calculated overall velocity as a function of number of parallel chains. Note that both velocities increase almost linearly with increase in number of chains.

\section{Discussion}

We had previously assessed the effect of size of model on transverse propagation velocity by comparing the transverse velocity on square models of different sizes, namely $3 \times 3,5 \times 5$, and $7 \times 7$. However, a rectangular model, where one dimension is held constant at 10 cells, should give a more accurate assessment of the boundary/edge effects (e.g., see Wang et al. [20]) on transverse velocity. Therefore, $10 \times 3,10 \times 5,10 \times 7,10 \times 10$, and $10 \times 20$ models were used for comparison. In addition, the transverse velocities were compared at two different degrees of cell coupling, namely $0 / 0$ and 100/100. It was found that transverse velocity (Fig. 5B) and overall velocity (Fig. 5C) both increased almost linearly with increase in number of parallel chains when there were no gj-channels $(0 / 0)$. In 
Table 2: Summary of the results obtained for cardiac muscle

\begin{tabular}{|c|c|c|c|c|c|c|c|c|c|c|c|c|}
\hline \multirow{2}{*}{$\begin{array}{c}\text { No. of } \\
\text { Chains } \\
\text { in } \\
\text { parallel }\end{array}$} & \multicolumn{3}{|c|}{ TPT (msec) } & \multicolumn{3}{|c|}{$\begin{array}{c}\text { Transverse velocity }(\mathrm{cm} / \\
\mathrm{sec})\end{array}$} & \multicolumn{3}{|c|}{ Overall velocity $(\mathrm{cm} / \mathrm{sec})$} & \multicolumn{3}{|c|}{ Ratios } \\
\hline & $\begin{array}{c}0 / 0 \\
\text { A }\end{array}$ & $\begin{array}{c}100 / 0 \\
\text { B }\end{array}$ & $\begin{array}{c}100 / 100 \\
C\end{array}$ & $\begin{array}{l}\text { O/0 } \\
\text { D }\end{array}$ & $\begin{array}{c}100 / 0 \\
E\end{array}$ & $\begin{array}{l}100 / 100 \\
F\end{array}$ & $\begin{array}{l}0 / 0 \\
\text { G }\end{array}$ & $\begin{array}{c}100 / 0 \\
H\end{array}$ & $\begin{array}{c}100 / 100 \\
1\end{array}$ & $\mathbf{A} / \mathbf{C}$ & F/D & I/G \\
\hline 3 & 15.6 & 6.6 & 1.9 & 0.21 & 0.48 & 1.68 & 27.9 & 65.9 & 229 & 8.2 & 8.0 & 8.2 \\
\hline 5 & 17.1 & 11.0 & 3.9 & 0.37 & 0.58 & 1.64 & 43.0 & 66.8 & 189 & 4.4 & 4.4 & 4.4 \\
\hline 7 & 18.4 & 12.9 & 5.8 & 0.52 & 0.74 & 1.66 & 56.3 & 80.2 & 178 & 3.2 & 3.2 & 3.2 \\
\hline 10 & 17.6 & 16.8 & 8.6 & 0.82 & 0.86 & 1.67 & 84.4 & 88.4 & 173 & 2.0 & 2.0 & 2.0 \\
\hline 20 & 18.0 & 17.2 & 15.2 & 1.69 & 1.77 & 2.00 & 166 & 174 & 196 & 1.2 & 1.2 & 1.2 \\
\hline
\end{tabular}

Each chain consisted of 10 cells, and the number of chains placed in parallel was varied from 3 to 20 .

The number of gj-channels, longitudinally and transversely, is indicated by the column headings: 0/0,100/0, and 100/100.

TPT is the total propagation time, measured as the elapsed time between when the first AP and last AP crossed the zero potential level.

Overall velocity (both longitudinal and transverse components) was calculated from the measured TPT and the distance traveled. Each myocardial

cell was assumed to be $150 \mu \mathrm{m}$ in length and $16 \mu \mathrm{m}$ in diameter.

contrast, when there was high cell coupling (100/100), the transverse velocity (Fig. 5B) and overall velocity (Fig. 5C) were nearly flat. Consistent with this, the TPT for 100/ 100 increased almost linearly, and that for $0 / 0$ was almost flat (Fig. 5A).

The conclusion that there is lesser and lesser effect of gjchannels in larger and larger networks is consistent with the fact that the ratios of TPT, $0 / 0$ to $100 / 100$, and of transverse velocity and overall velocity becomes lower and lower as the size of the network is increased (Table 2).

Figure 5 also indicates that the facilitory or potentiating effect of many gi-channels on transverse velocity and overall velocity, as compared to the pure electric field (EF) mechanism (0/0), becomes less and less as the network is increased in size. That is, the two curves are converging. This suggests that the EF mechanism alone can account for the measured propagation velocities in the intact myocardium.

Figure 5, in addition, indicates that the boundary/edge effects are less important when there is high cell coupling, because transverse velocity and overall velocity are relatively flat with increase in number of parallel chains. In contrast, when there are no gj-channels $(0 / 0)$, transverse velocity and overall velocity keep increasing with increase in number of parallel chains [24]. This suggests that the edge effects act to slow velocity, in agreement with our previous report $[16,19]$. Presumably, velocity should saturate or level off when the number of parallel chains is increased sufficiently.

Related to this is the fact that the propagation velocity in the first half of the network (chains A-J) is speeded up when another 10 chains are added in parallel (chains K-
T), as can be seen in Figure 2. Thus, adding the second half of the network speeds propagation in the first half because the edge effect is pushed further downstream.

Although Figure 5 and Table 2 show velocities that are higher than those found physiologically in the intact heart, the absolute values can be reduced by decreasing the excitability of the basic circuit units. We previously demonstrated that decreasing the excitability of the basic units slows propagation velocity [25].

When there were no gj-channels $(0 / 0)$, there was usually a large delay between the first AP (from stimulated cell A1 - A2) and the second AP recorded. This delay could be reduced by increasing $R_{B T}$, the bundle termination resistances at the two ends of the bundle. Adding a capacitance in series with $R_{B T}$ also acted to reduce this delay. We believe that this peculiar delay is due to an edge effect at the top of the network. When a cell pair near the middle of the network was stimulated (instead of cells A1 - A2), then no such delay was observed.

Transverse propagation is known to occur physiologically in cardiac muscle through the thickness of the ventricular wall (i.e., transmurally), from the endocardial surface to the epicardial surface $[26,27]$. The transmural conduction velocity in canine heart was substantially faster in the endo to epi direction $(48 \pm 6 \mathrm{~cm} / \mathrm{sec})$ than in the reverse direction $(37 \pm 6 \mathrm{~cm} / \mathrm{sec})$ [26]. There were heterogenties in number of gap junctions through the wall thickness. Since the physiological transverse conduction velocity is much higher than what we have obtained for transverse transmission by the EF mechanism, there must be gap junctions oriented in the transverse direction. 


\section{Gj-channels : Longit./Transv. $=\mathbf{1 0 0} / \mathbf{1 0 0}$}
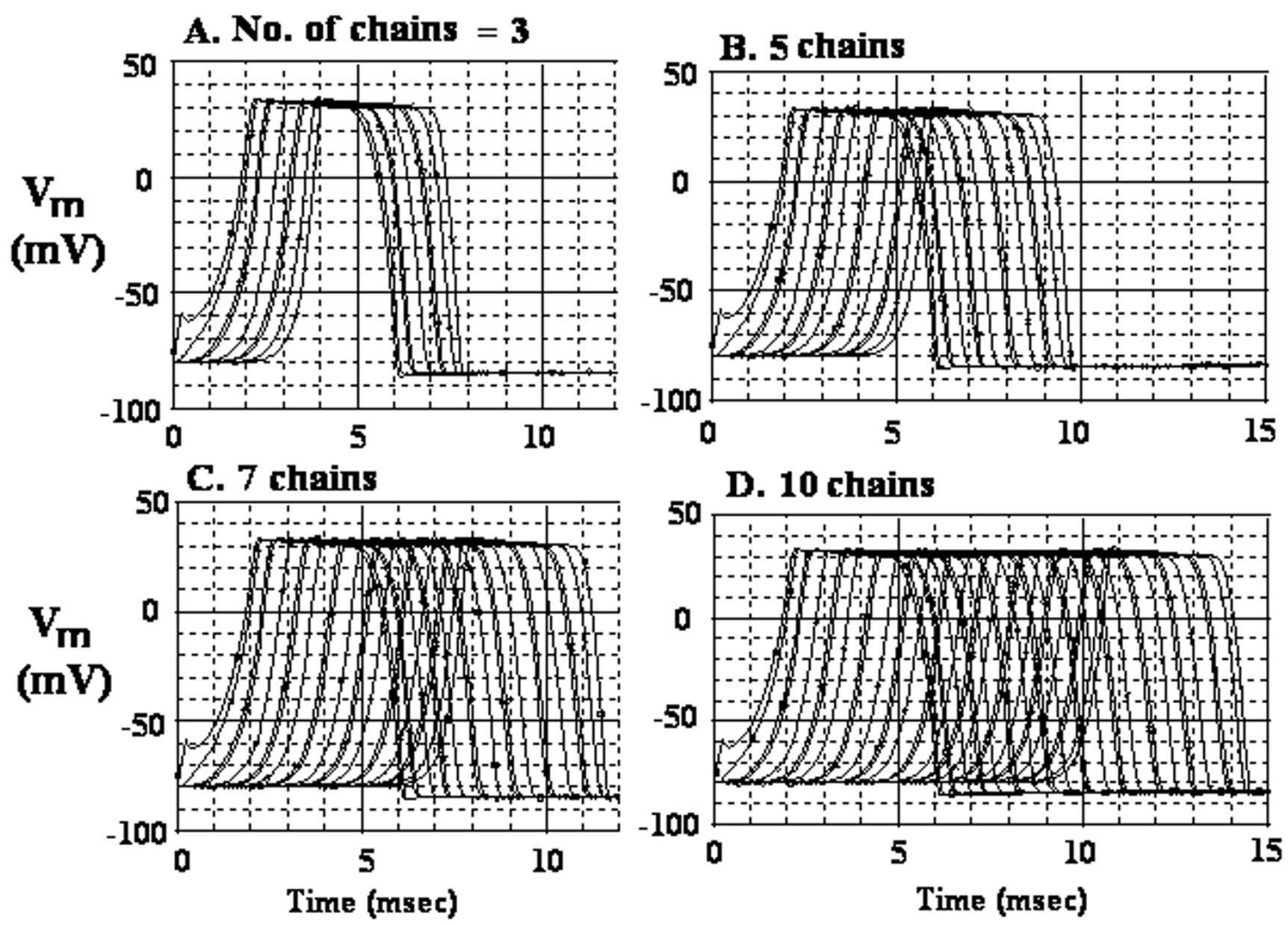

Figure 3

AP records obtained in the cardiac muscle model when there were many $(\mathrm{I} 00)$ gj-channels, both longitudinally and transversely (I00/I00). The transverse gj-channels were placed only at the ends of the chains (e.g., at cells $\mathrm{AlO}-\mathrm{BIO}$, cells $\mathrm{BI}-\mathrm{CI}$, cells $\mathrm{CIO}$ DI0, etc), giving a zigzag pattern. Voltage probes were placed only in cells I, 5 , and 10 of each chain. A: 3 chains in parallel. B: 5 chains in parallel. C: 7 chains in parallel. D: 10 chains in parallel.

In summary, the present study demonstrates that strong edge effects affect transverse velocity and overall velocity when there are no gj-channels ( $0 / 0$ category). Thus, propagation by the EF mechanism is slowed by edges. In contrast, when there is strong cell coupling, transverse velocity and overall velocity are not much affected by edge effects. If the network is large enough, propagation by the EF mechanism is almost as fast as in the case of high coupling.

\section{Study limitations}

The present study has some limitations. (1) First, the $20 \times$ 10 model size used is relatively small as compared to regions of the intact heart. Therefore, the importance of the edge effects described here is unclear with respect to relevance to the whole heart. (2) Second, the computational method used here has some limitations in comparison to some other methods that have been used [28-31]. (3) Third, the placement of the transverse gj-channel only at the ends of the chains, to create a zigzag pattern of transverse propagation, may not represent the situation in normal intact heart. However, a zigzag pathway has been observed in canine atria under pathophysiological conditions [23]. (4) Fourth, when there were no longitudinal or transverse gj-channels, the junctional delays were longer than those reported experimentally [6,31]. (5) The impor- 
No. of gj-channels: longit. / transv.

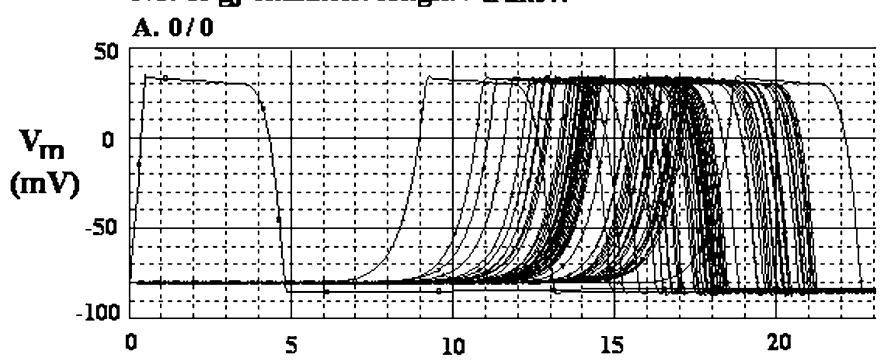

C. $10 / 10$

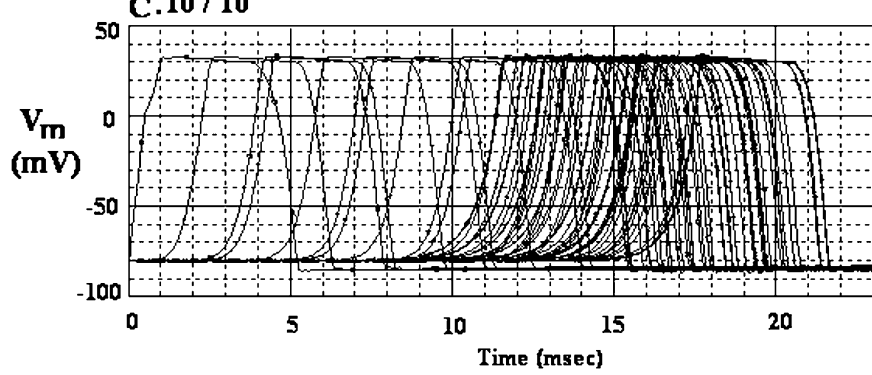

B. $1 / 1$

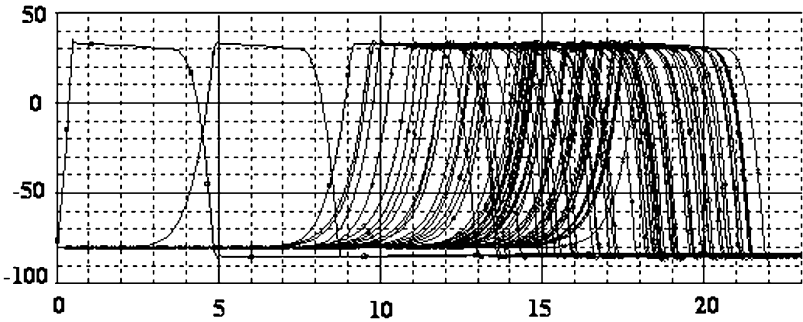

D. $100 / 100$

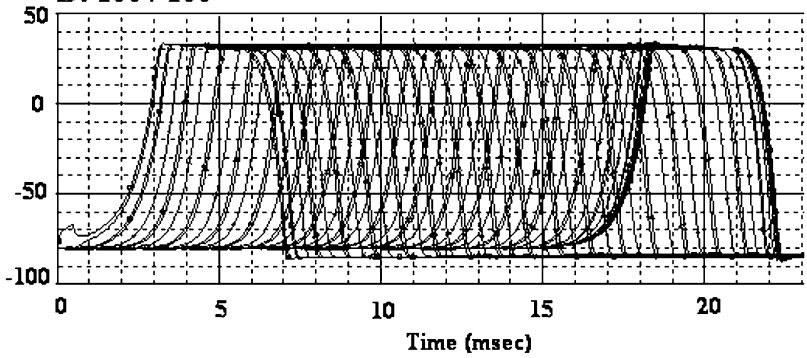

Figure 4

Cardiac action potential records obtained from the $10 \times 20$ model ( 10 cells per chain, 20 parallel chains) for different numbers of gj-channels. The number of gj-channels, longitudinal to transverse, is indicated as a ratio. A: 0/0 channels. B: I/I channels. C: I0/I0 channels. D: 100/100 channels. Voltage probes were placed only in the end cells of each chain (cells I and I0), to reduce complexity.

\section{Graphic plot of data from expanded model of cardiac muscle} gj-channels : longit. / transv.
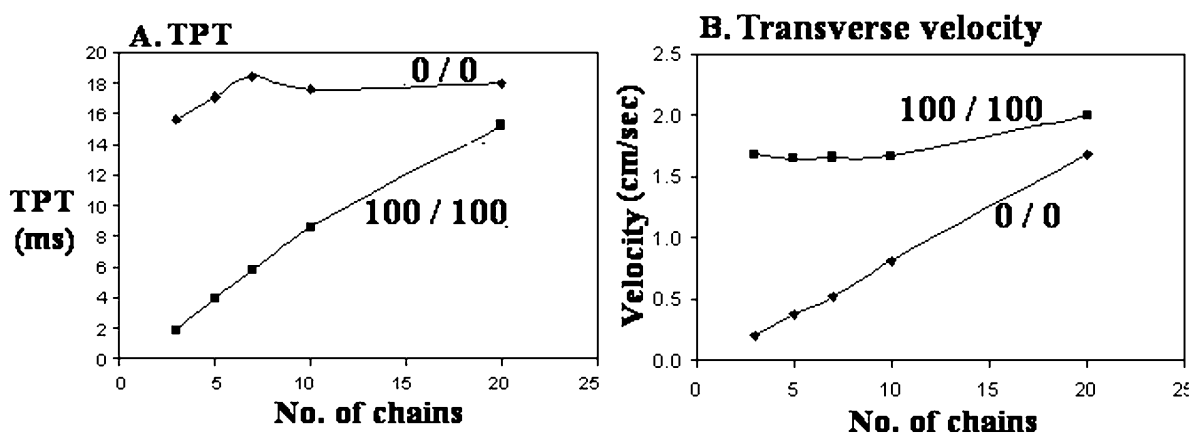

C. Overall Velocity

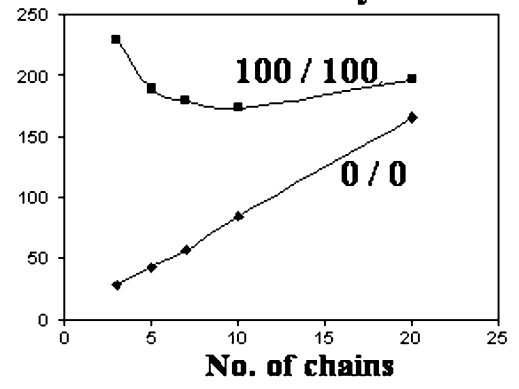

Figure 5

Graphic summary of the results obtained for no gj-channels $(0 / 0)$ or 100 gj-channels $(100 / 100)$. The number of parallel chains is given on the abscissa. A: TPT measured. B: Transverse velocity calculated from the TPT and distance traveled. C: Overall velocity calculated from the TPT and distance traveled. The myocardial cells were assumed to be I50 $\mu \mathrm{m}$ in length and I6 $\mu \mathrm{m}$ in diameter. 
tance and relevance of edge effects in intact heart is not clear at the present time, but the ventricular wall contains several layers of fibers running in different directions.

\section{References}

I. Sperelakis N, Mann JE Jr: Evaluation of electric fieldchanges in the cleft between excitable cells. J Theor Biol 1977, 64:7I-96.

2. Picone JB, Sperelakis N, Mann JE Jr: Expanded model of the electric field: Hypothesis for propagation in cardiac muscle. Math Computer Modeling 1991, 15:17-35.

3. Sperelakis N, Ramasamy L: Propagation in cardiac muscle and smooth muscle based on electric field transmission at cell junctions: An analysis by PSpice. IEEE-Eng Med Biol 2002, 21:130-143.

4. Sperelakis N: An electric field mechanism for transmission of excitation between myocardial cells. Circ Res 2002, 91:985-987.

5. Hogues $\mathrm{H}$, Leon LJ, Roberge FA: A model study of electric field interactions between cardiac myocytes. IEEE Trans Biomed Eng 1992, 39:1232-1243.

6. Rohr S: Role of gap junctions in the propagation of the cardiac action potential. Cardiovasc Res 2004, 62(2):309-322.

7. Rohr S, Kucera JP, Fast VG, Kleber AG: Paradoxical improvement of impulse conduction in cardiac tissue by partial cellular uncoupling. Science 1997, 275:84I-844.

8. Sperelakis N: Cell Physiology Sourcebook. $3^{\text {rdedition. Chapter }}$ 24: Cable properties and propagation of action potentials. Appendix I: Academic Press 200 I:407-4I I.

9. Cohen SA: Immunocytochemical localization of rHI sodium channel in adult rat heart atria and ventricle. Presence in terminal intercalated disks. Circulation 1994, 74: |07|-1096.

10. Kucera JP, Rohr S, Rudy Y: Localization of sodiumchannels in intercalated disks modulates cardiac conduction. Circ Res 2002, 91 : I I 76- I I82.

II. Sperelakis N, Murali KPV: Combined electric field and gap junctions on propagation of action potentials in cardiac muscle and smooth muscle in PSpice simulation. J Electrocardiol 2003, 36(4):279-293.

12. Morley GE, Vaidya D, Samie FH, Lo CW, Taffet SM, Delmar M, Jalife $\mathrm{J}$ : Characterization of conduction in the ventricles of normal and heterozygous Cx43 knockout mice using optical mapping. J Cardiovasc Electrophysiol 1999, 10:1361-1375.

13. Tamaddon HS, Vaidya D, Simon AM, Paul DL, Jalife J, Morley GE: High resolution optical mapping of the right bundle branch in connexin 40 knockout mice reveals low conduction in the specialized conduction system. Circ Res 2000, 87:929-936.

14. Gutstein DE, Morley GE, Tamaddon H, Vaidya D, Schneider MD, Chen J, Chien KR, Stuhlmann H, Fishman Gl: Conduction slowing and sudden arrhythmic death in mice with cardiac restricted inactivation of connexin43. Circ Res 200I, 88:333-339.

15. Vaidya D, Tamaddon HS, Lo CW, Taffet SM, Delmar M, Morley GE: Null mutation of connexin 43 causes slow propagation of ventricular activation in the late stages of mouse embryonic development. Circ Res 2001, 88: I I96-I 202.

16. Sperelakis N, Kalloor B, Ramasamy L: Boundary effects influence velocity of transverse propagation of simulated cardiac action potentials. Theor Biol \& Med Modeling 2005, 2:36.

17. Sperelakis N: Propagation of action potentials between parallel chains of cardiac muscle cells in PSpice simulation. Can J Physiol Pharmacol 2003, 81:48-58.

18. Sperelakis N, Kalloor B: Transverse propagation of action potentials between parallel chains of cardiac muscle and smoothmuscle cells in PSpice simulations. Biomed Eng Online 2004, 3:5.

19. Ramasamy L, Sperelakis N: Gap-junction channels inhibit transverse propagation in cardiac muscle. Biomed Eng Online 2005, 4:7.

20. Wang S, Leon LJ, Roberge FA: Interactions between adjacent fibers in a cardiac muscle bundle. Ann Biomed Eng 1996, 24:662-674.

21. Sperelakis N, Ramasamy L: Propagation in cardiac muscle and smooth muscle based on electric field transmission at cell junctions: An analysis by PSpice. IEEE-Eng Med Biol 2002, 21:130-143

22. Ramasamy L, Sperelakis N: Repolarization of the action potential enabled by $\mathrm{Na}+$ channel deactivation in PSpice simula- tion of cardiac muscle propagation. Theor Biol \& Med Modeling 2005, 4: 17.

23. Koura T, Hara M, Takeuchi S, Ota K, Okada Y, Miyoshi S, Watanabe A, Shiraiwa K, Mitamura H, Kodama I, Ogawa S: Anisotropic conduction properties in canine atria analyzed by high-resolution opticalmapping. Circulation 2002, 105:2092-2098.

24. Ramasamy L, Sperelakis N: Effect of transverse gap-junction channels on transverse propagation in an enlarged PSpice model of cardiac muscle. Theor Biol Med Modeling 2006, 3: I4.

25. Sperelakis N, Kalloor B: Effect of variation in membrane excitability on propagation velocity of simulated action potentials for cardiac muscle and smooth muscle in the electric field model for cell to cell transmission of excitation. IEEE-Eng Med Biol 2004, 5 I:2216-2219.

26. Poelzing S, Akar FG, Baron E, Rosenbaum DS: Heterogeneous connexin 43 expression produces electrophysiological heterogeneities across ventricular wall. Am J Physiol: Heart \& Circ Physiol 2003, 286:H200I-H2009.

27. Poelzing S, Rosenbaum DS: Altered connexin43 expression produces arrhythmia substrate in heart failure. Am J Physiol: Heart \& Circ Physiol 2004, 287:HI762-HI770.

28. Diaz PJ, Rudy Y, Plonsey R: Intercalated discs as a cause for discontinuous propagation in cardiac muscle: A theoretical simulation. Ann Biomed Eng 1983, II:177-189.

29. deCastro M, Hofer E, Munuzuri AP, Gomez-Gesteira M, Plank G, Schafferhofer I, Perez-Munuzuri V, Perez-Villar V: Comparison between the role of discontinuities in cardiac conduction and in a one-dimensional hardware model. Physical Review E 1999, 59(5):5962-5969.

30. Henriquez AP, Vogel R, Muller-Borer BJ, Henriquez CS, Weingart R, Cascio WE: Influence of dynamic gap junction resistance on impulse propagation in ventricular myocardium: a computer simulation study. Biophys / 200I, 8I:2I I2-2I2I

31. Spach MS, Heidlage JF: The stochastic nature of cardiac propagation at a microscopic level: electrical description of myocardial architecture and its application to conduction. Circ Res 76:366-380.
Publish with Biomed Central and every scientist can read your work free of charge

"BioMed Central will be the most significant development for disseminating the results of biomedical research in our lifetime. "

Sir Paul Nurse, Cancer Research UK

Your research papers will be:

- available free of charge to the entire biomedical community

- peer reviewed and published immediately upon acceptance

- cited in PubMed and archived on PubMed Central

- yours - you keep the copyright
BioMedcentral 